\title{
Using narratives to impact health policy- making: a systematic review
}

Racha Fadlallah ${ }^{1,2}$, Fadi El-Jardali ${ }^{1,2}$, Mohamed Nomier ${ }^{1}$, Nour Hemadi ${ }^{1}$, Khurram Arif ${ }^{1}$, Etienne V. Langlois ${ }^{3}$ and Elie A. Akl ${ }^{1,4^{*}}$ (D)

\begin{abstract}
Background: There is increased interest in using narratives or storytelling to influence health policies. We aimed to systematically review the evidence on the use of narratives to impact the health policy-making process.

Methods: Eligible study designs included randomised studies, non-randomised studies, process evaluation studies, economic studies, qualitative studies, stakeholder analyses, policy analyses, and case studies. The MEDLINE, PsycINFO, Cochrane Library, Cumulative Index to Nursing and Allied Health Literature (CINAHL), WHO Global Health Library, Communication and Mass Media Complete, and Google Scholar databases were searched. We followed standard systematic review methodology for study selection, data abstraction and risk of bias assessment. We synthesised the findings narratively and presented the results stratified according to the following stages of the policy cycle: (1) agenda-setting, (2) policy formulation, (3) policy adoption, (4) policy implementation and (5) policy evaluation. Additionally, we presented the knowledge gaps relevant to using narrative to impact health policymaking.
\end{abstract}

Results: Eighteen studies met the eligibility criteria, and included case studies $(n=15)$, participatory action research $(n=1)$, documentary analysis $(n=1)$ and biographical method $(n=1)$. The majority were of very low methodological quality. In addition, none of the studies formally evaluated the effectiveness of the narrative-based interventions. Findings suggest that narratives may have a positive influence when used as inspiration and empowerment tools to stimulate policy inquiries, as educational and awareness tools to initiate policy discussions and gain public support, and as advocacy and lobbying tools to formulate, adopt or implement policy. There is also evidence of undesirable effects of using narratives. In one case study, narrative use led to widespread insurance reimbursement of a therapy for breast cancer that was later proven to be ineffective. Another case study described how the use of narrative inappropriately exaggerated the perceived risk of a procedure, which led to limiting its use and preventing a large number of patients from its benefits. A third case study described how optimistic 'cure' or 'hope' stories of children with cancer were selectively used to raise money for cancer research that ignored the negative realities. The majority of included studies did not provide information on the definition or content of narratives, the theoretical framework underlying the narrative intervention or the possible predictors of the success of narrative interventions.

Conclusion: The existing evidence base precludes any robust inferences about the impact of narrative interventions on health policy-making. We discuss the implications of the findings for research and policy.

Trial registration: The review protocol is registered in PROSPERO International prospective register of systematic reviews (ID = CRD42018085011).

Keywords: Narrative, storytelling, health policy-making, systematic review

\footnotetext{
*Correspondence: ea32@aub.edu.lb

${ }^{1}$ Center for Systematic Review for Health Policy and Systems Research,

American University of Beirut, Beirut, Lebanon

${ }^{4}$ Department of Internal Medicine, American University of Beirut, Beirut,

Lebanon

Full list of author information is available at the end of the article
}

(C) The Author(s). 2019 Open Access This article is distributed under the terms of the Creative Commons Attribution 4.0 International License (http://creativecommons.org/licenses/by/4.0/), which permits unrestricted use, distribution, and reproduction in any medium, provided you give appropriate credit to the original author(s) and the source, provide a link to the Creative Commons license, and indicate if changes were made. The Creative Commons Public Domain Dedication waiver (http://creativecommons.org/publicdomain/zero/1.0/) applies to the data made available in this article, unless otherwise stated. 


\section{Background}

Narratives, also referred to as storytelling, exemplars and testimonials, can be used to convey information because they are easily understandable and memorable [1, 2]. While there is no commonly accepted definition of a narrative, it is generally agreed that it should provide an account of an individual's experience and include appealing detail, characters and some plot [3-7]. It may be communicated through a wide range of formats, including verbal (narrated), print, audio and video $[8,9]$.

Narratives can facilitate information processing and provide value and emotional appeal to the information provided $[8,10]$. Additionally, people can relate to narrative information regardless of their level of literacy, expertise or culture [11, 12]. These narratives have been demonstrated to be both memorable and persuasive [13, 14]. Several theoretical perspectives have been considered to explain the persuasiveness of narrative information $[8,15-20]$; see Table 1 for a description of these models.

The communication literature offers some insights on the effects of different ways of communicating information on behaviour. First, individuals make choices based on incorporating both factual and narrative information; narrative information influences individuals' choices directly (system 1 ) and indirectly via cognitions (system 2 ), and the persuasiveness of narrative or statistical information varies depending on the characteristics and experiences of the recipients [21, 22]. These insights imply that it is naive to assume that it is sufficient to present people with 'facts', and expect that they will weigh these in a rational manner and act accordingly [23].

There is growing recognition among experts in the field of public policy-making of the need to incorporate narrative as an important component of the broad evidence base required to inform complex policy-making processes $[23,24]$. This is particularly so given that policy decisions are often value-driven and political, not just evidence-based choices [25], and that policy-makers and public health professionals operate on a different hierarchy of evidence compared to researchers [26]. For instance, policy-makers prefer information that is concise, appealing and relevant to current health policy debates [27-29].

As highlighted by Cairney and Kwiatkowski [30], policy-makers attach cognitive and emotional shortcuts to thoughts and action, often without fully understanding the reasons for that action; therefore, 'bombarding' them with evidence can be less effective than presenting them with compelling stories or using other framing techniques to harness their cognitive biases. In this sense, narrative information can be more useful than statistical data, partly because the latter can be seen as too complex, not policy-relevant, tedious or lacking context sensitivity [31,32].

The use of narratives in the policy environment can help identify important policy issues, point to problems with
Table 1 Description of models relevant to narratives

\begin{tabular}{ll}
\hline Model & Description \\
\hline Elaboration likelihood & Under this widely adopted ELM, \\
& persuasive situations involve a \\
& central and a peripheral route [15]. \\
In the central or systematic route, & people think deeply about the \\
& message and assess the validity \\
& of the information. In the peripheral \\
& or heuristic route, people assess \\
characteristics of the message, \\
such as its attractiveness; the \\
personal relevance of the message \\
determines the route that will be \\
used for its perception [15]
\end{tabular}

Green's transportationimagery model

Entertainment overcoming resistance mode

Kahneman's two-system way of thinking
This model states that the persuasiveness of a narrative which people are engaged in the story events, a phenomenon called "transportation" [17]. In this model, recipients are totally emotionally with the story characters and events. Therefore, they are less likely to counter-argue the narrative claims; this contrasts with the ELM, where recipients elaborate on the story with their thoughts, ideas and previous experiences [16]

According to this model, when recipients are engaged within the story (Transportation), or when they relate to characters similar to themselves (Identification), they are less likely to be resistant to receive the message and change their attitude and behaviour [18, 20]. According to this theory, several narrative characteristics could determine how much the recipients can accept the message such as the level of suspense and imagery in the narrative and the degree of realism that recipients can associate with the story [19]

Kahneman distinguishes between two systems of thinking: 'System 1' (Thinking Fast) is the intuitive way of thinking and making decisions (i.e. relying on heuristic or cognitive shortcuts that develop as part of people's experiences), while' System 2' (Thinking Slow) is the analytical and deliberate way of making decisions (i.e. weighing the advantages and disadvantages) [7]. Systems 1 and 2 are differentially activated by different aspects of narratives depends on the extent to immersed in the story and engage

existing policies, provide evidence that a programme or law is working as intended, and assist policy-makers in thinking about the consequences of policy options [10, 27, 31, 33]. For instance, personal stories of breast cancer have been key in creating significant changes in health policies and 
legislative allocations in the United States [33]. While there is a growing number of reports on the use of narrative-based interventions to shape policy-making, we are not aware of any systematic synthesis of that body of evidence. The objective of this study was to systematically synthesise the evidence on the use of narratives to impact health policy-making.

\section{Methods}

\section{Study design and definitions}

We conducted a systematic review of the literature, following standard methodology. We registered the review protocol in the PROSPERO International prospective register of systematic reviews (ID $=$ CRD42018085011) and we followed the PRISMA guidelines for reporting systematic reviews.

For the purpose of this study, we conceptualised a narrative as an illustration of an experience in a story-like format, presented in either the first or the third person [2]. The terms that we considered as referring to "narratives' include storytelling, anecdotes, exemplars, testimonials and policy narratives [7,21]. Given that the goal of this review was to inform those interested in using narrative information to affect health policy-making, we restricted our eligibility to studies where the primary purpose of using a narrative was to affect policy-making (i.e. narrative as a planned intervention). The narrative could be presented in any format (e.g. verbal, print, audio/radio, video) or perspective (first- or third-person narrative).

Public policy refers to government policy and includes programmes, plans, rules, legislation, guidelines, statements or positions taken by government or governmental departments with the aim of achieving population-level change (whether at the sub-national, national or international level) [34]. This excludes policies confined to one institution only or those related to individual-level clinical interventions [35]. We only considered public policies pertaining to health.

\section{Eligibility criteria}

We used the following eligibility criteria:

Type of studies: We included a range of types of studies to account for the diverse literature on narratives and the complex nature of evidence in the policy sector [36]. Specifically, we included randomised studies, non-randomised studies (e.g. cohort studies, before and after studies, retrospective studies, and cross-sectional studies), process evaluation studies, economic studies, qualitative studies, stakeholder analyses, policy analyses and case studies. We excluded news articles, books, letters, commentaries, opinion pieces, proposals, reviews and studies published in abstract format only. We also excluded studies where narrative was mentioned as part of the background information only.
We did not exclude studies based on date of publication or language.

- Population: We included studies where the narrative intervention targeted legislators, policymakers, representative of professional associations, governmental representatives or any other individuals involved in health policy-making. We excluded studies where the narrative intervention targeted patients or people in their individual capacity (e.g. in a clinical setting).

- Interventions: Narratives used as standalone or as part of a multi-component intervention with the primary purpose of influencing health policy-making in a real-world setting. We excluded studies where the narrative was not an explicit or deliberate component of the intervention. We also excluded studies that assessed message-framing only or that used narrative for information delivery without any link to the policy cycle.

- Comparison: We included studies regardless of whether or not they have a comparison group.

- Outcomes: We included studies that examined the influence of narrative information on any of the stages of health policy-making in a real-world setting [37]. We stratified findings according to the stages of policy-making, as defined by the Stages Heuristic framework, as follows: (1) agenda-setting, (2) policy formulation, (3) policy adoption, (4) policy implementation and (5) policy evaluation (see Table 2 for a detailed definition of the different stages) [37-40]. We excluded studies that assessed proxy outcomes such as changes in knowledge, beliefs, attitude, preferences or intentions. We also excluded studies that involved individuals making hypothetical decisions. Additionally, we excluded studies that assessed the impact of narrative on public opinion only or that examined policy-making processes beyond the health or health-related sector.

- Settings: We included any country, state or community

\section{Search strategy}

We searched the following electronic databases up to February 2017: MEDLINE, PsycINFO, Cochrane Library, Cumulative Index to Nursing and Allied Health Literature (CINAHL), WHO Global Health Library, and Communication and Mass Media Complete. The search strategy combined the two different concepts of 'narrative' and 'public policy'. To generate a list of search terms for each concept, we first undertook an initial targeted search of the literature, followed by an analysis of the text words contained in the title and abstract of potentially relevant studies as well as of the index terms used to describe the 
Table 2 Description of stages heuristic framework

\begin{tabular}{|c|c|}
\hline Stage & Description \\
\hline Agenda-setting & $\begin{array}{l}\text { Process through which an issue or problem } \\
\text { reaches the policy agenda and gets the } \\
\text { attention of policy-makers; this usually } \\
\text { occurs when an interest group demands } \\
\text { government action on a problem, or when } \\
\text { there is public disagreement over ways in } \\
\text { which a problem should be addressed }\end{array}$ \\
\hline Policy formation & $\begin{array}{l}\text { A set of policy alternatives and solutions is } \\
\text { generated and the public administration } \\
\text { concerned examines the various policy } \\
\text { options. Coalitions of actors strive, through } \\
\text { the use of advocacy strategies, to gain } \\
\text { priority for one specific option. }\end{array}$ \\
\hline Policy adoption & $\begin{array}{l}\text { Decisions are made at the } \\
\text { governmental level, resulting } \\
\text { in a decision that favours one } \\
\text { or more options to addressing a } \\
\text { given problem. Decisions are given } \\
\text { a legal force or legitimised as a } \\
\text { result of the public statements or } \\
\text { actions of government officials; this } \\
\text { includes executive orders, laws and } \\
\text { appropriations, rules and regulations, } \\
\text { and administrative and court decisions } \\
\text { that set policy directions }\end{array}$ \\
\hline Policy implementation & $\begin{array}{l}\text { This includes the actions and } \\
\text { mechanisms whereby adopted } \\
\text { policies are brought into practice; } \\
\text { social, economic, technological, and } \\
\text { political conditions significantly } \\
\text { influence the implementation } \\
\text { stage of public policies }\end{array}$ \\
\hline Policy evaluation & $\begin{array}{l}\text { This assesses whether policies } \\
\text { have achieved their intended goals } \\
\text { and objectives; it covers the appraisal } \\
\text { of their content, their implementation } \\
\text { and their effects }\end{array}$ \\
\hline
\end{tabular}

article. Additionally, we reviewed the search strategies of relevant systematic reviews. This helped generate an initial list of terms relevant to each of the two concepts of 'narrative' and 'public policy', respectively including, for example, narrative, narration, testimonial, anecdote, exemplar, and story, and policy, public policy, health policy, reform, lobbying, regulation, law enforcement, policy-making, government, law, legislation, decree, jurisprudence, advocacy, decision-making, etc.

The search included both free-text words and medical subject headings. We used the Boolean operator 'OR' to combine the terms within each concept and the Boolean operator 'AND' to combine the different concepts. We did not use any search filter for study type, language or date of publication. The search strategy was validated by an experienced medical librarian (Additional file 1).

We complemented the electronic database searches with a variety of approaches to identify additional literature, including grey literature. We manually searched Google Scholar and relevant journals like Health Affairs. We also screened the reference lists of included studies and relevant systematic reviews. In addition, we contacted the authors of relevant articles and conference proceedings for further information or additional material.

\section{Study selection}

We conducted the selection process in two phases, namely title and abstract screening, wherein teams of two reviewers screened the titles and abstracts of identified citations, in duplicate and independently, for potential eligibility and retrieved the full text of studies judged as potentially eligible by at least one of the two reviewers, and full-text screening, wherein two reviewers screened the full texts in duplicate and independently for eligibility, using a standardised and pilot-tested screening form, and resolving disagreements by discussion or with the help of a third reviewer.

Prior to the selection process, all the reviewers participated in a calibration exercise using a randomly selected sample of 100 citations. The calibration exercise allowed us to pilot the eligibility criteria to ensure they are applied in the same way across reviewers, thus enhancing the validity of the process.

\section{Data abstraction}

Two reviewers abstracted data from eligible studies in duplicate and independently using standardised and pilot-tested data abstraction forms. They conducted a calibration exercise on a randomly chosen sample to ensure adequate agreement and resolved disagreement by discussion or with the help of a third reviewer if consensus could not be reached.

Abstracted data focused on the variables of study design, timeframe and background story; health topic, organiser, target population and setting; narrative definition and theoretical framework used; format of narrative (verbal, print, audio, video) and characteristics of the narrative information (plot and characters); characteristics of the intervention used to deliver the narrative; and policy outcomes assessed.

\section{Quality assessment}

We planned to assess risk of bias and quality of reporting of the included studies, using tools appropriate for the study design. However, we did not assess the risk of bias of included studies given that existing tools to critically appraise the types of studies retrieved have not been validated, and thus have strong limitations at this stage (as well as lack of consensus). We did assess the quality of reporting of case studies according to the reporting standards developed by Rodgers et al. [41]. These standards consist of 13 items grouped into four sections, as (1) describing the design ( 4 standards); (2) describing the data collection (3 standards); (3) describing the data analysis (1 standard); and (4) interpreting the results (5 standards). 


\section{Data synthesis}

We conducted thematic analysis and presented the results in a narrative way, stratified according to the following stages of the policy cycle: (1) agenda-setting, (2) policy formulation, (3) policy adoption, (4) policy implementation and (5) policy evaluation [37]. Two reviewers were involved in the identification of the themes. Where applicable, we provided direct quotations. Additionally, we assessed the knowledge gaps related to our topic. We assessed five domains most commonly used in published evidence gap maps, i.e. study design, interventions, setting, population and outcomes [42].

\section{Results}

\section{Study selection}

Figure 1 shows the PRISMA flow chart summarising the study selection process. Out of 12,698 citations, we identified 18 eligible studies. We excluded 438 articles at the full-text screening phase because they did not focus on planned narratives as part of the intervention $(n=258)$, did not focus on health or health-related issues $(n=18)$, did not target population-level policy changes in a real world setting $(n=135)$, were not a study design of interest (e.g. commentary, review, magazine) $(n=25)$, or contained duplicate information $(n=2)$ (Additional file 2).

\section{Characteristics of studies}

Table 3 describes the characteristics of the 18 included studies in terms of study design, timeframe, background story, health topic, target population, organisers of narrative-based interventions, country, narrative definition and theoretical framework used, format of narrative (verbal, print, audio, video), characteristics of the narrative information (plot and characters), characteristics of the intervention used to deliver the narrative, and policy outcomes assessed.

The study designs were case studies $(n=15)$ [33, 43-56], participatory action research $(n=1)$ [57], documentary analyses $(n=1)$ [58] and biographical methods $(n=1)$ [59]. Thirteen studies were from high-income countries (Australia $(n=4)$, Republic of Ireland $(n=1)$, United States of America $(n=8)$ and United Kingdom $(n=1))$, four studies were from middle-income countries (Georgia $(n=1)$, China $(n=1)$, and South Africa $(n=2))$ and one study was from low-income countries (Rwanda $(n=1)$ ); one study included data from both Republic of Ireland and Australia [43].

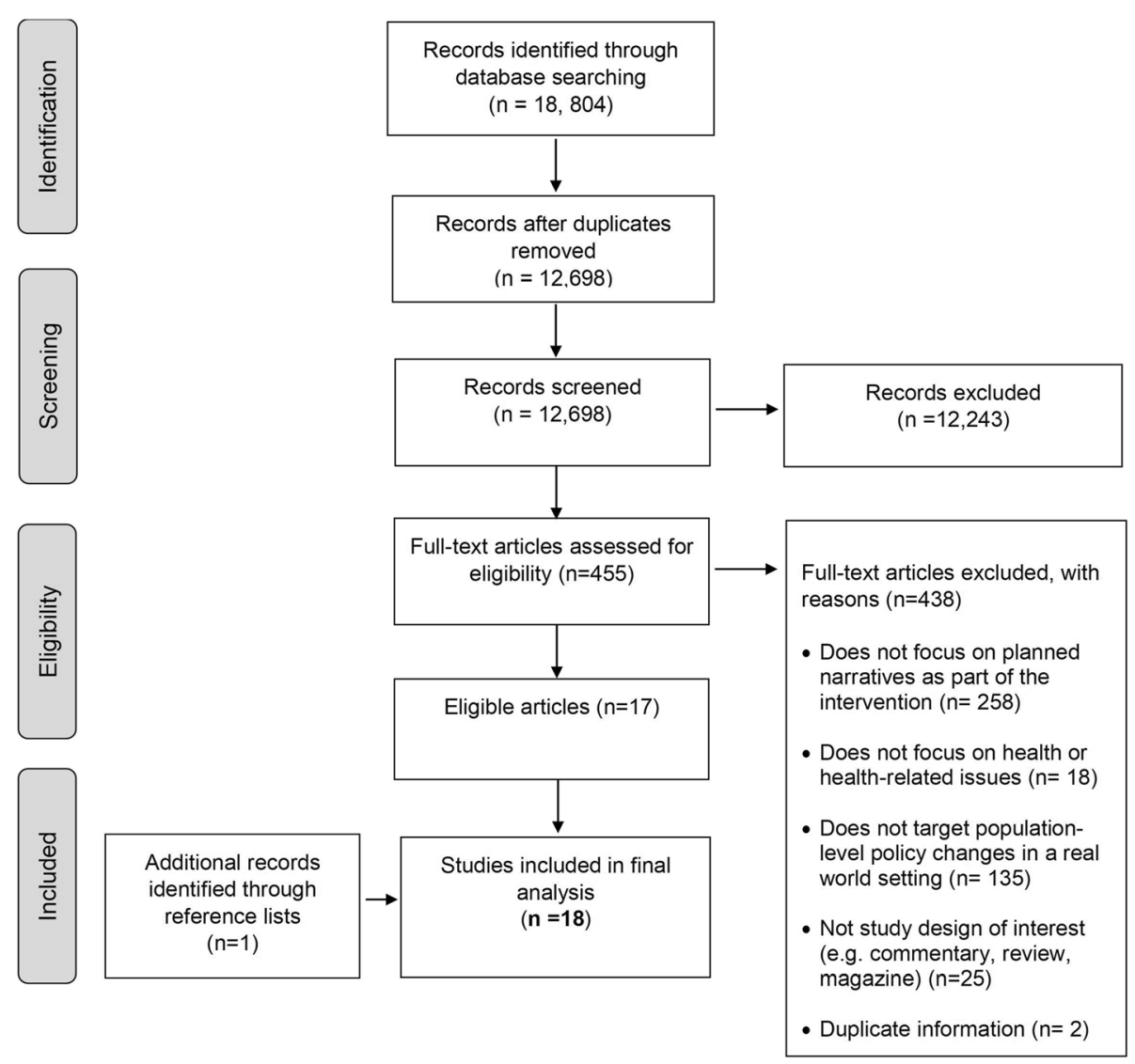

Fig. 1 Study flowchart 


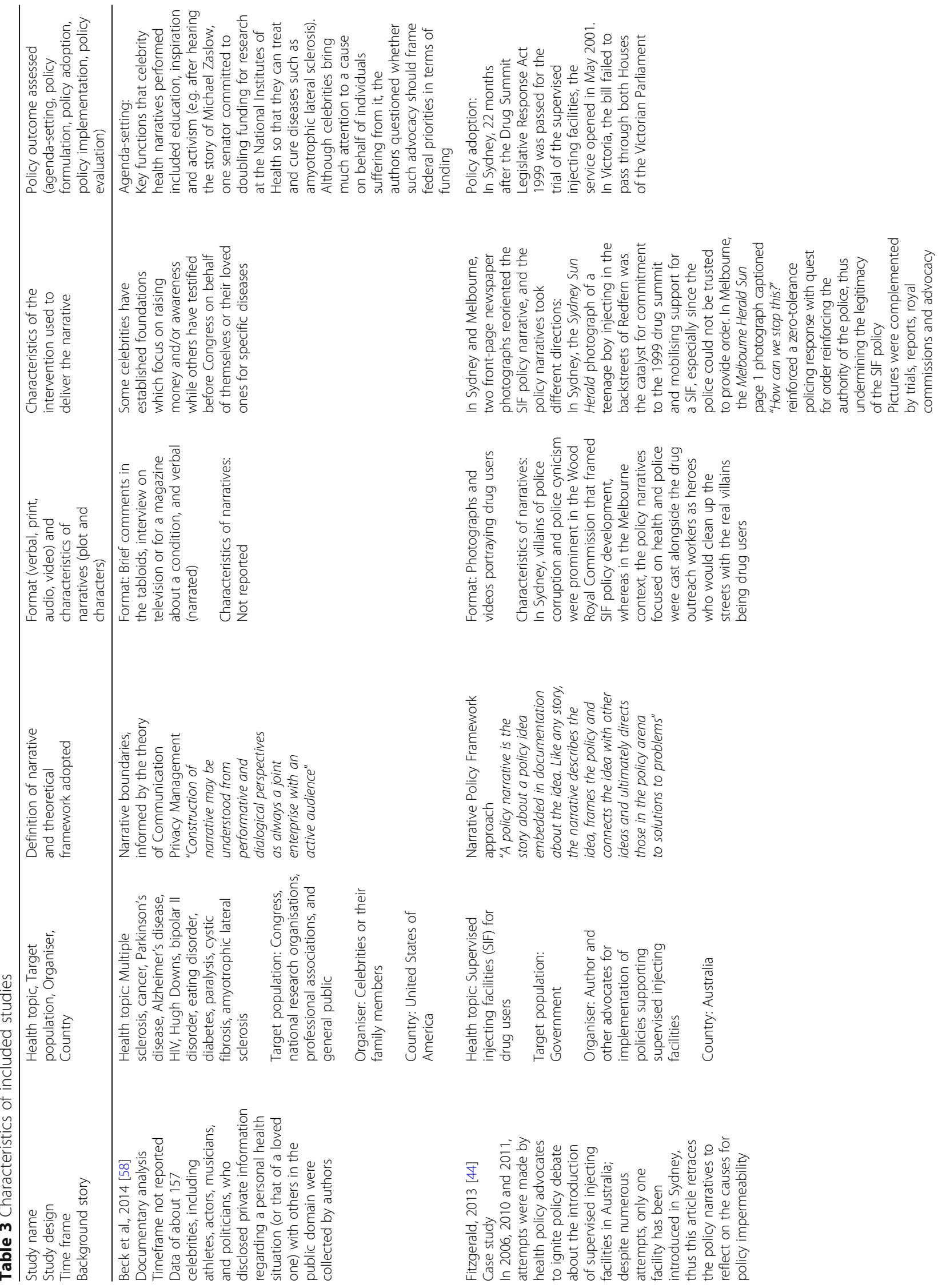




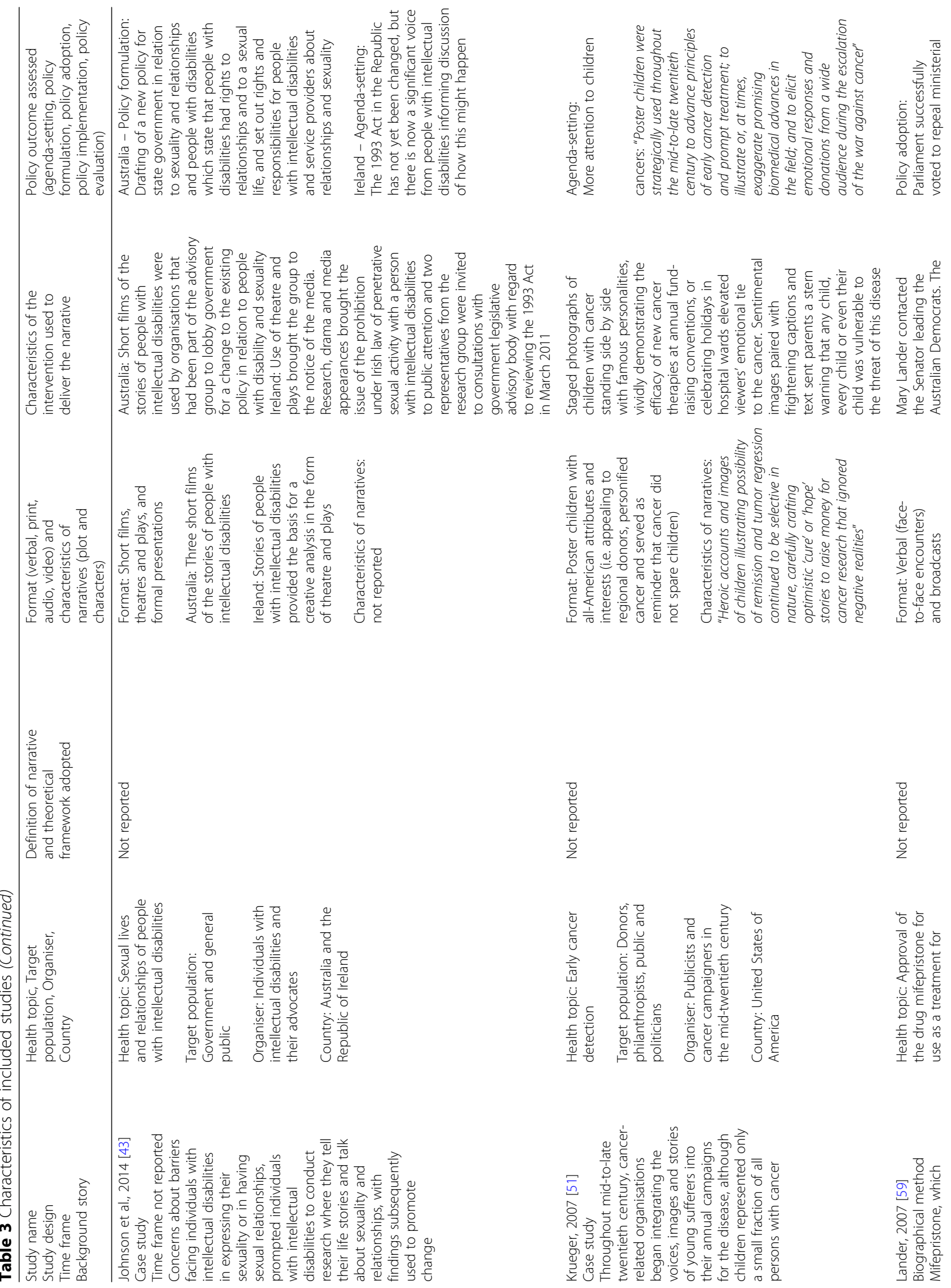




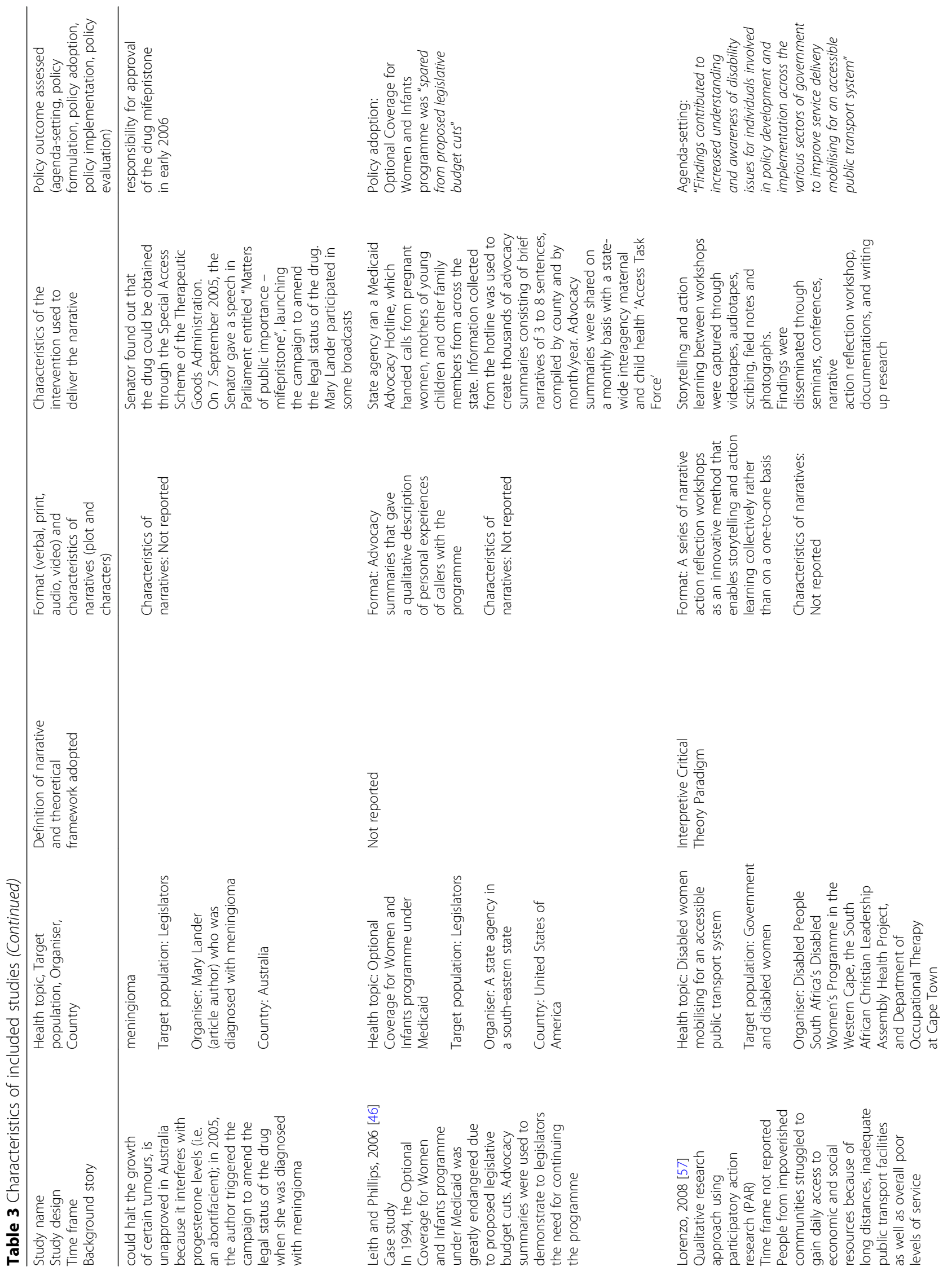




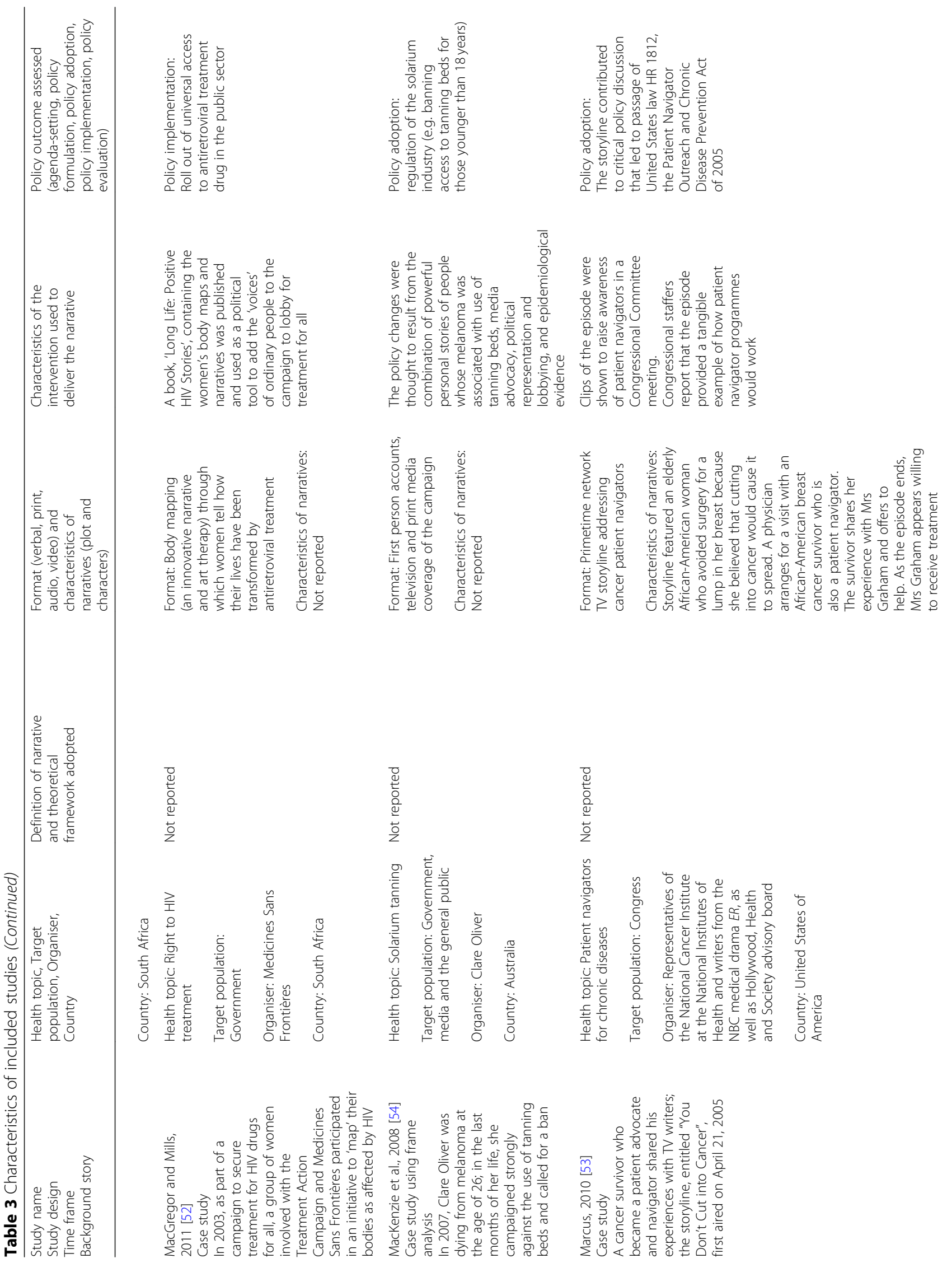




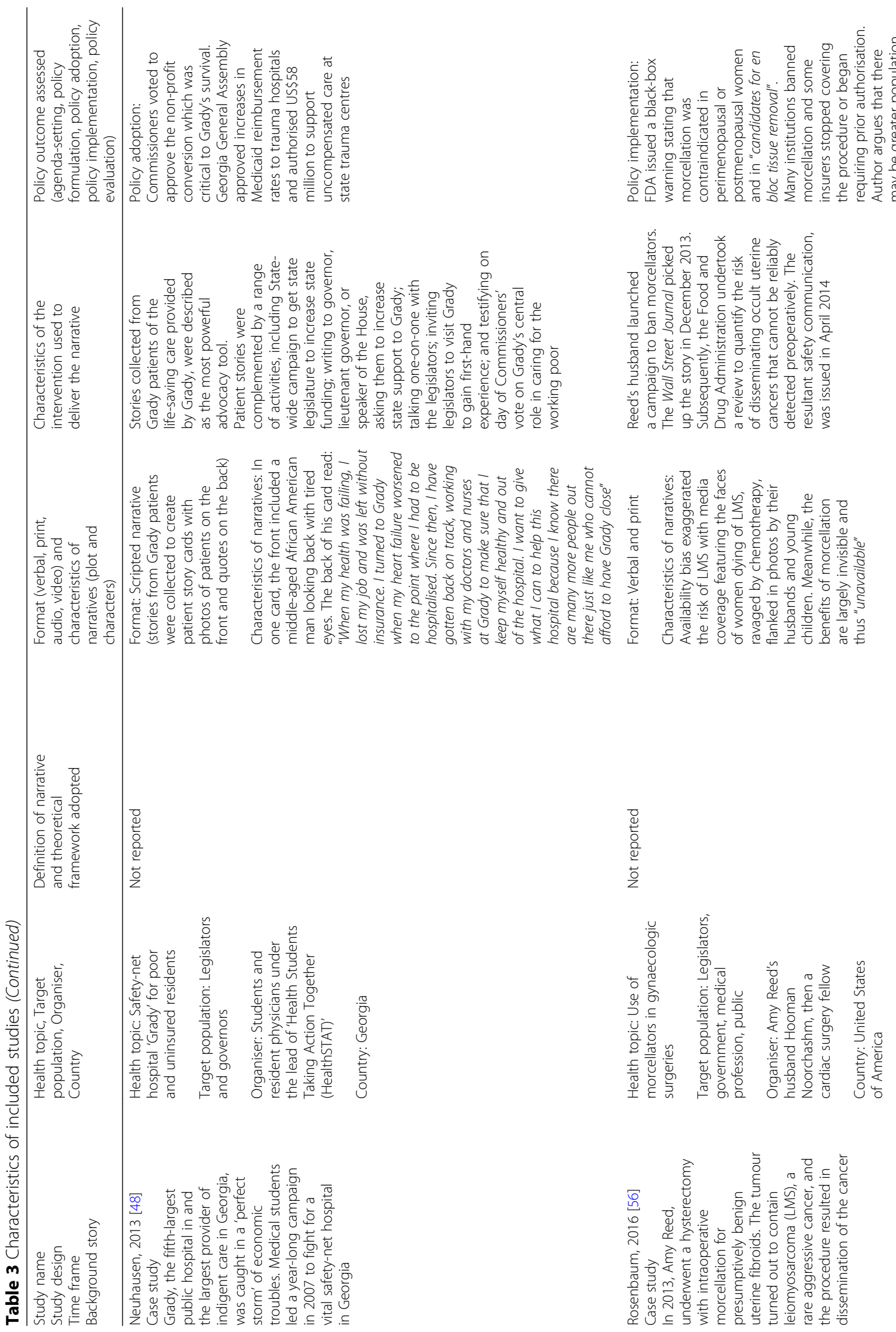




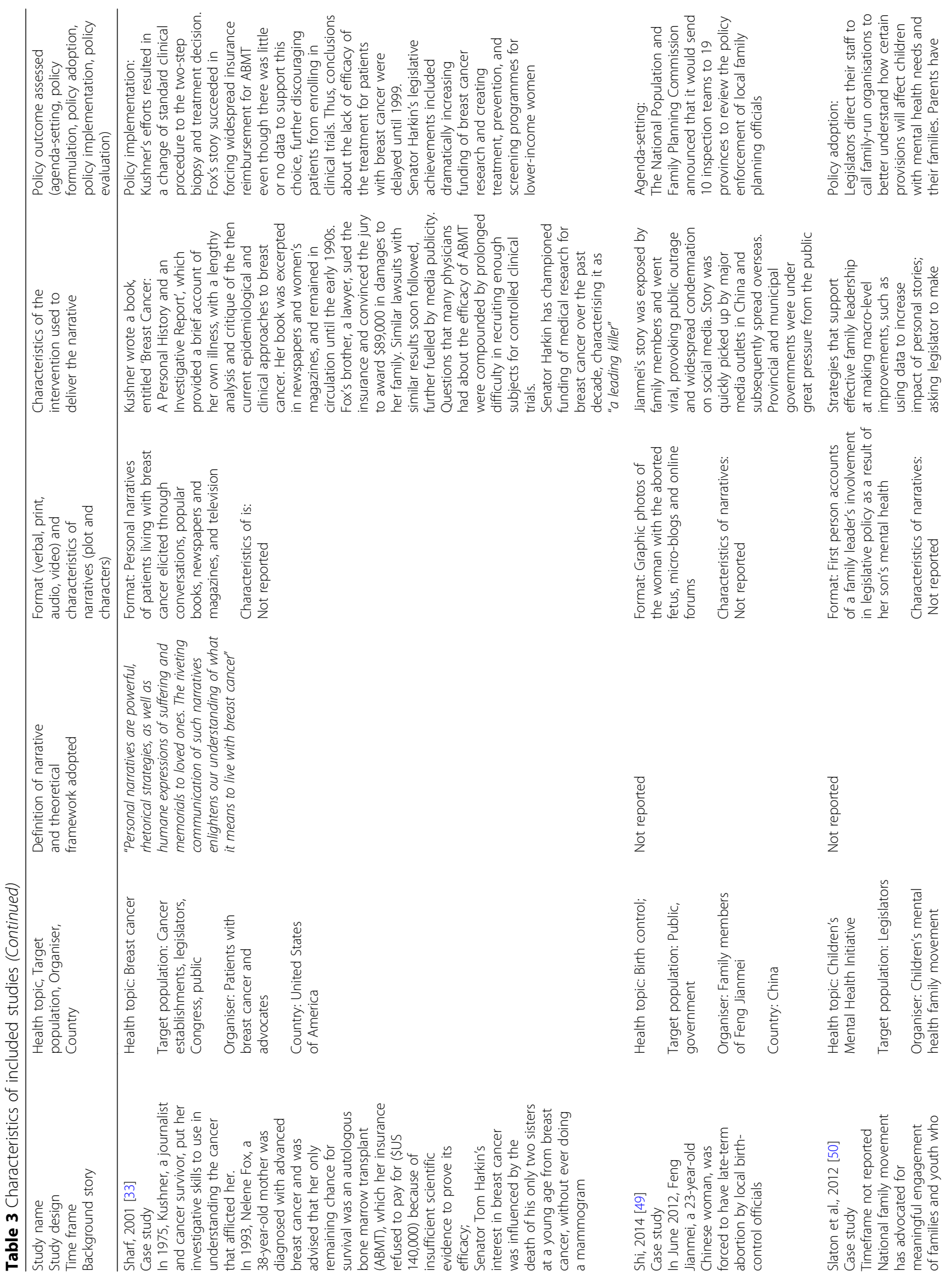




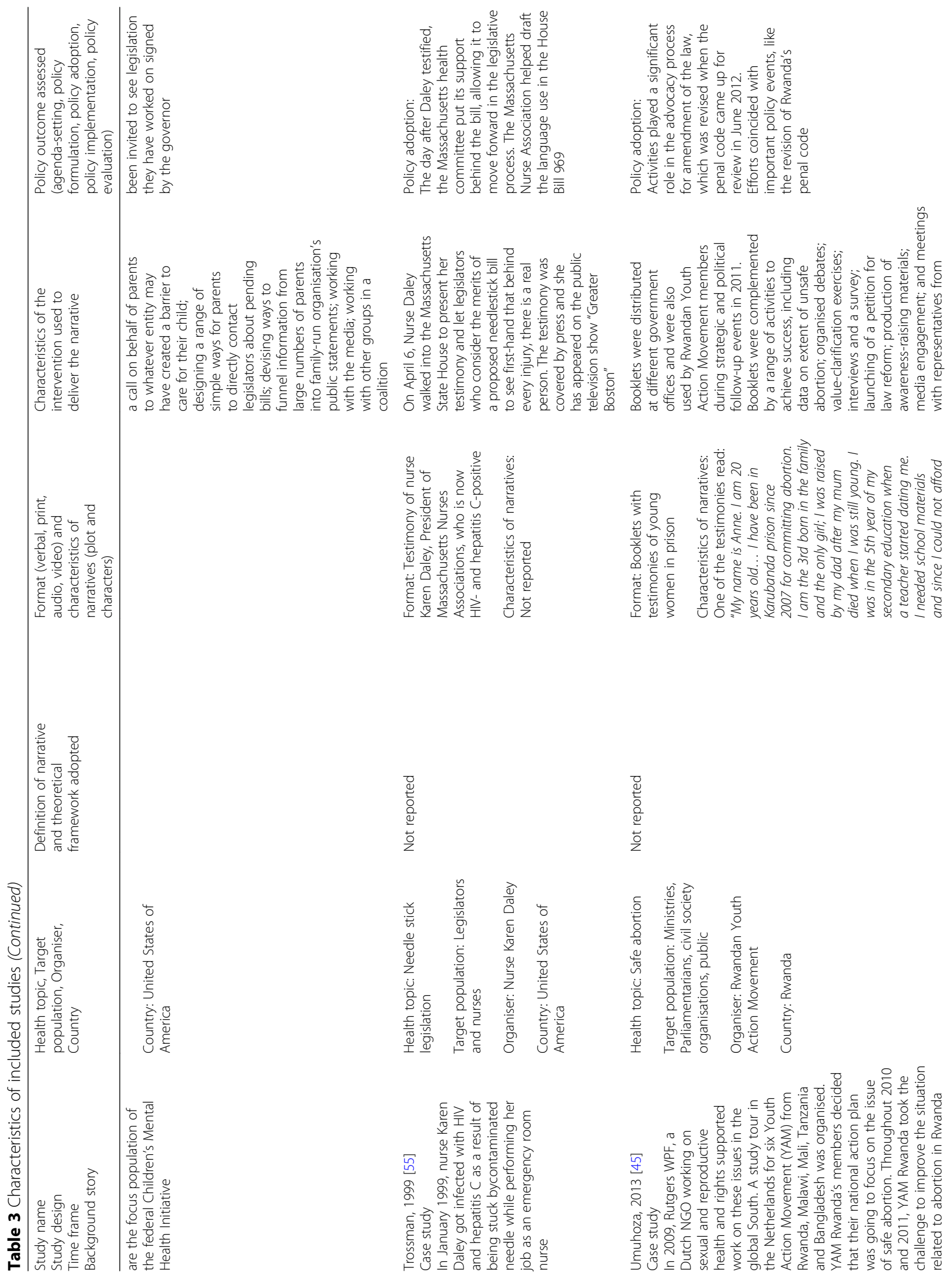




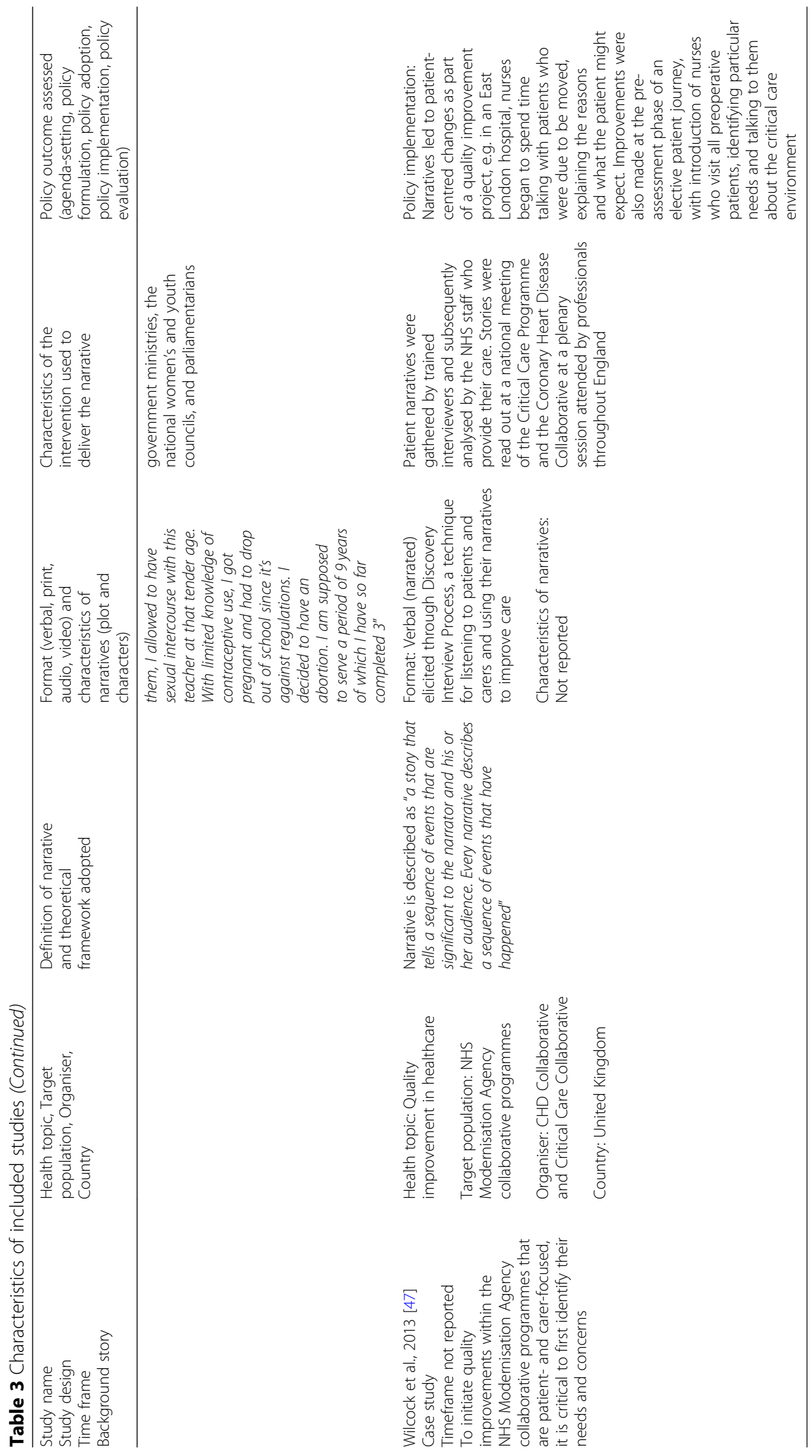


Eight studies targeted policy-makers, legislators and/or governors only $[44,46,48,50,52,53,55,59]$, one targeted national healthcare organisations only [47], and nine targeted multiple stakeholders including government and the public [33, 43, 45, 49, 51, 54, 56-58]. In one of the studies, the target audience was TV viewers; however, we only focused on the findings specific to policy-makers which was relevant to our question [53].

The included studies covered the topics of solarium tanning $(n=1)$, HIV/AIDS $(n=1)$, individuals with disabilities $(n=2)$, patient navigators for chronic diseases $(n=1)$, supervised injecting facilities for drug users $(n=1)$, abortion $(n=2)$, Medicaid Optional Coverage for Women and Infants programme $(n=1)$, needlestick injuries $(n=1)$, safety-net hospital for poor and uninsured residents $(n=1)$, birth control $(n=1)$, mental health initiatives for children $(n=1)$, cancer $(n=2)$, use of morcellators in gynaecologic surgeries $(n=1)$, approval of mifepristone for use as treatment for meningioma $(n=1)$, and quality improvement in healthcare $(n=1)$. One study focusing on personal celebrity health narratives examined a range of diseases, including multiple sclerosis, cancer, Parkinson's disease, Alzheimer's disease, HIV, Hugh Downs, bipolar II disorder, eating disorder, type 1 diabetes, paralysis, cystic fibrosis and amyotrophic lateral sclerosis [58].

Four of the included studies provided a definition for narrative $[33,44,47,58]$ and three described the theoretical framework underpinning the narrative intervention $[44,57,58]$. All but four studies used a meta-narrative, which combined the stories of a large number of people to convey a thematic, systemic story as opposed to focusing on a single event or individual (i.e. episodic stories). The narrative information was presented in different formats, with some studies utilising more than one format. These formats included television appearances $(n=3)[54,58,59]$, entertainment education (prime-time network TV storyline) $(n=1)$ [53], short films, theatre and plays $(n=1)$ [43], magazines and journal prints $(n=2)$ $[56,58]$, books $(n=2)[33,52]$, narrative action reflection workshops $(n=1)$ [57], video materials $(n=2)$ [44, 56], posters and photos $(n=3)[44,49,51]$, booklets with testimonies $(n=1)$ [45], advocacy summaries of personal experiences $(n=1)$ [46], story cards with photos of patients on front and quotes on back $(n=1)$ [48], micro-blogs and online forums $(n=1)$ [49], and verbal (narrated) $(n=6)[33,47,50,55,58,59]$.

In seven studies, the narrative information was presented alone $[33,47,51,52,55,58,59]$, whereas in 11 studies, the narrative was part of a multi-component intervention leading to the reported change in outcome [43-46, 48-50, 54, 56, 57]. Components besides narratives included organised debates, values clarification exercises, interviews and surveys in four universities, a petition for law reform and media involvement [45]; quantitative data [46]; state-wide campaign, writing to governor, lieutenant governor, or speaker of the House, talking one-on-one with the legislators, and inviting legislators to gain first-hand experience [48]; parental meetings, working with other groups in a coalition, quantitative data and media engagement [50]; research and media appearances [43]; seminars, documentation and conferences [57]; trials, reports, royal commissions and advocacy efforts [44]; media advocacy, direct political representation and lobbying and epidemiological evidence [54]; and campaign, media coverage, and review of research [56].

The included studies examined the influence of narratives on the policy outcomes of agenda-setting $(n=5)$, policy formulation $(n=1)$, policy adoption $(n=9)$, and policy implementation $(n=4)$; none looked at policy evaluation. One of the studies included data from two countries, and reported impact at different levels of the policy-making process [43]. None of the studies conducted actual evaluation of effectiveness or provided explicit evidence for the link between the intervention and the outcome.

\section{Methodological appraisal}

Additional file 3 presents the detailed assessment of the reporting of included case studies according to the standards by Rodgers et al. [41]. None of the cases studies met all 13 reporting standards. The median score was 4 (out of a maximum score of 13). Only four studies met more than half of the reporting standards [43, 44, 47, 54].

\section{Influence on policy outcomes}

We present below the findings stratified according to the stages heuristic framework of the public policy process.

\section{Agenda-setting}

One participatory action research [57], one documentary analysis [58] and three case studies [43, 49, 51] examined the influence of narrative on agenda-setting.

Lorenzo [57] reported that a series of narrative action reflection workshops enabled storytelling and action learning by women with disability in Cape Town. These women were able to mobilise collectively for change regarding an accessible public transport system as a strategy for social inclusion. The findings have "contributed to increasing the understanding and awareness of disability issues for people involved in policy development and implementation across the various sectors of government to improve service delivery mobilizing for an accessible public transport system so that they had equal opportunities to participation in social and economic development" [57].

Johnson et al. [43] examined the contribution of inclusive qualitative research studies (via life stories) to policy-making related to people with disabilities' right to 
relationships and to a sexual life in Ireland. As a result of research, drama and media appearances, the issue of the prohibition of penetrative sexual activity with a person with intellectual disabilities under Irish law was brought to public attention. In March 2011, two representatives from the research group were invited to consultations with the government's legislative advisory body, the Law Reform Commission, with regard to reviewing the 1993 Act - "The Act in the Republic has not yet been changed, but there is now a significant voice from people with intellectual disabilities informing discussion of how this might happen" [43].

Beck et al. [58] conducted a documentary analysis of newspaper articles, letters to the editors of magazines and newspapers, televised interviews, and online databanks to identify celebrities, including athletes, actors, musicians and politicians, who have publicly shared personal narratives regarding their health situation (or that of a loved one). The authors found that the key functions that celebrity health narratives performed were education, inspiration and activism. Celebrity narratives have contributed to raising money and awareness and have also led to doubling funding for research at the National Institutes of Health for certain diseases.

Krueger [51] conducted a case study of how cancer-related organisations were integrating, beginning in the late 1940s, the voices, images and stories of young sufferers into their annual campaigns as tools for education, awareness and inspiration. The author remarked: "Poster children were strategically used throughout the mid-to-late twentieth century to advance principles of early cancer detection and prompt treatment; to illustrate or, at times, exaggerate promising biomedical advances in the field; and to elicit emotional responses and donations from a wide audience during the escalation of the war against cancer" [51].

Shi [49] described the story of Feng Jianmei, a 23-yearold Chinese woman who was forced to have late-term abortion by local birth-control officials. Her story was exposed by family members through graphic photos, micro-blogs and online forums, provoking public outrage and widespread condemnation on social media sites. In response to tremendous pressure from the public, the National Population and Family Planning Commission announced that it would send 10 inspection teams to 19 provinces to review the policy enforcement of local family planning officials.

\section{Policy formulation}

Johnson et al. (discussed above) [43], explored the contribution of inclusive qualitative research studies to change in policy and legislation related to people with disabilities' right to relationships and to a sexual life, also in Australia. Twenty-five people with intellectual disabilities told their life stories and talked about sexuality and relationships. Three short films of the stories were subsequently produced and used to lobby government for a change to the existing policy. The new policy draft clearly set out rights and responsibilities for people with intellectual disabilities and service providers about relationships and sexuality.

\section{Policy adoption}

Eight case studies [44-46, 48, 50, 53-55] and one biographical study [59] examined the influence of narrative on policy adoption.

MacKenzie et al. [54] reviewed television and print media coverage of the campaign to regulate solaria initiated by Clare Oliver before her death from melanoma in late 2007. A frame analysis was conducted of all direct and attributed statements about the causes of, and responsibility for, Oliver's melanoma, and about the legacy of her campaign. Oliver's story was influential in securing regulations across all states and territories to ban access to tanning beds for those younger than 18 years.

Marcus et al. [53] assessed the educational and behavioural impact of an $E R$ (NBC drama) storyline that addressed cancer patient navigators on primetime TV viewers. Clips of the TV episode were used by Congressional staffers to raise awareness of patient navigators in a Congressional Committee meeting. Congressional staffers reported that the episode provided a tangible example of how patient navigator programmes would work and contributed to "critical policy discussion that led to passage of US law HR 1812, the Patient Navigator Outreach and Chronic Disease Prevention Act of 2005" that provides funds to model programmes that would help patients to access healthcare services.

Fitzgerald [44] retraced the policy narratives related to the introduction of supervised injecting facilities (SIFs) in Australia in documentary materials. Narrative was used as an advocacy tool to inform government of the impact of street injecting on a local community. The narrative intervention was one component of a multi-faceted intervention, including trials, reports and advocacy to promote SIF in two different parts of Australia (Sydney and Melbourne). In Sydney, SIF policy development was framed as a response to police corruption (i.e. police were viewed as villains), whereas in Melbourne, the policy narratives focused on health and welfare of drug users (with the police, here, viewed as heroes). These two framings created a different pathway for policy development. In Sydney, 22 months after the Drug Summit Legislative Response Act 1999 was passed for the trial of the SIF, the service opened in May 2001. In Melbourne, the bill failed to pass through both Houses of the Victorian Parliament.

Umuhoza et al. [45] reflected on the use of personal stories as advocacy tools to mobilise action for law reform. Narrative was part of a multicomponent intervention 
initiated by Rwandan Youth Action Movement to put the new abortion law into effect in 2012. The use of testimonies and stories of young people gave a 'face' to the issue of unsafe abortion. These activities "played a significant role in the advocacy process for amendment of the [abortion] law which was revised when the penal code came up for review in June 2012" [45]. These efforts also coincided with important policy events, which opened a window of opportunity for action.

Leith and Phillips [46] presented three short case studies illustrating how qualitative techniques and consumer narratives can serve as advocacy tools to inform public policy. We focused on the case study on Optional Coverage for Women and Infants Medicaid programme as it is health related. To demonstrate to state legislators the need for continuing the programme, the state agency in a south-eastern state provided state legislators with advocacy summaries from their constituent areas. Hotline information was used to create thousands of these advocacy summaries consisting of brief narratives of three to eight sentences that gave a qualitative description of the personal experiences of callers with the system. The narratives were also supplemented by data regarding the success of the programme. Based on these narrative accounts, "legislators were able to see first hand the impossible situations families in poverty were experiencing, and the Optional Coverage for Women and Infants program was ultimately spared from proposed legislative budget cuts" [46].

Neuhausen [48] reported how hundreds of students and resident physicians fought for the survival of 'Grady', the fifth-largest public hospital and the largest provider of indigent care in Georgia. Narrative was one component of a national campaign and advocacy efforts to get state legislature to approve the non-profit conversion of Grady and to increase state funding. Stories from Grady patients describing the life-saving care provided by Grady were collected to create story cards, with photos of patients on the front and quotes on the back. These stories were described as the most powerful advocacy tool. The commissioners voted to approve the non-profit conversion which was critical to Grady's survival. The Georgia General Assembly also approved "increases in Medicaid reimbursement rates to trauma hospitals and authorized \$58 million to support uncompensated care at state trauma centers" [48].

Slaton et al. [50] described the stories of four familyled organisations and the impact of their advocacy efforts on systems of care for mental health. We specifically focused on one family leader's story of involvement in legislative policy. Narratives of parents of children with mental health problems was one component of a multifaceted approach that also included networking with other families and organisations, speaking with legislators, engaging in advocacy and involving the media. According to the family leader involved in that case study, legislators now direct their staff to call the family-led organisation to better understand how certain provisions will affect children with mental health needs and their families. Additionally, parents have been invited to see legislation they have worked on being signed by the governor [50].

Trossman [55] described how the President of Massachusetts Nurses Associations used her personal story to push for needlestick legislation in Massachusetts. Following her infection with HIV and hepatitis $\mathrm{C}$ as a result of being pricked by a contaminated needle, Nurse Daley presented her testimony at the Massachusetts State House and let legislators who consider the merits of a proposed needlestick bill to see that there is a real person behind every injury. The day after she testified, the Massachusetts health committee put its support behind the bill, allowing it to move forward in the legislative process.

Lander [59] described how her campaign to amend the legal status of the drug mifepristone in Australia was triggered in 2005 when she was diagnosed with meningioma. Although the drug could halt the growth of tumours, it was unapproved in Australia because of its potential use as an abortifacient. The campaign involved email exchanges and ongoing contact with a Senator as well as participation in broadcasts to help raise awareness of the drug. In 2006, parliament successfully voted to repeal ministerial responsibility for approval of the drug mifepristone.

\section{Policy implementation}

Four case studies examined the role of narratives on policy implementation [33, 47, 52, 56].

MacGregor and Mills [52] described how, in an attempt to enhance access to antiretroviral drugs in South Africa in 2003, a group of women involved with the Treatment Action Campaign and Medicines Sans Frontières participated in an initiative to 'map' their bodies as affected by HIV. Through the body maps and personal accounts published alongside the maps, women told how their lives have been transformed by antiretroviral treatment. The women's body maps and narratives were published in a book, 'Long Life', which was subsequently used as a political tool to add the 'voices' of ordinary people to the campaign. These efforts contributed to the roll out of universal access to antiretroviral treatment drug in the public sector.

Wilcock et al. [47] reflected on the use of patient stories to inspire quality improvement within the NHS Modernisation Agency collaborative programmes. Patients' narratives were gathered by trained interviewers in one-toone semi-structured qualitative interviews and analysed by the NHS staff who provide their care. The stories were read out at a national meeting of the Critical Care Programme 
and the Coronary Heart Disease Collaborative. The authors presented two case studies illustrating how these narratives led to patient-centred changes as part of quality improvement projects within the NHS Modernisation Agency collaborative programmes in England.

Sharf [33] provided a historical view of how personal narratives of women living with breast cancer affected health policy. The author reported that personal breast cancer stories have inspired efforts by citizen advocates and legislators to provide better care and more resources for the disease (for example, changing of standard clinical procedure and creating treatment, prevention and screening programmes for lower-income women). However, the author also shed light on a case where narrative of breast cancer led to undesirable outcomes; in 1993, after being diagnosed with advanced breast cancer, Nelene Fox was advised by her doctors that her only remaining chance for survival was an autologous bone marrow transplant. Her insurance refused to pay for the procedure because the treatment was classified as experimental due to insufficient scientific evidence that it extended a patient's life. Fox's brother, a lawyer, sued the insurance and convinced the jury to award $\$ 89,000$ in damages to her family. Media publicity about the Fox case succeeded in forcing widespread insurance reimbursement, further discouraging patients from enrolling in clinical trials. Conclusions about the efficacy of the treatment were delayed until 1999 when the National Cancer Institute announced that autologous bone marrow transplant does not benefit people with breast cancer.

Rosenbaum [56] reflected on the case of 40-year-old Amy Reed who underwent a hysterectomy with intraoperative morcellation for presumptively benign uterine fibroids (which unknowingly contained leiomyosarcoma), thus causing it to disperse. Following her death, Reed's husband launched a campaign to ban morcellators which was picked up by The Wall Street Journal. Extensive media coverage featuring the faces of women dying of leiomyosarcoma exaggerated the risk of leiomyosarcoma, while the benefits of morcellation remained largely invisible and, thus, 'unavailable'. Subsequently, the Food and Drug Administration undertook a review to quantify the risk of disseminating occult uterine cancers that cannot be reliably detected preoperatively, 6 months later issuing a black-box warning stating that morcellation was contraindicated in perimenopausal or postmenopausal women and in "candidates for en bloc tissue removal". Many institutions banned morcellation and some insurers stopped covering the procedure or began requiring prior authorisation. The author explained that medical products are associated with two types of risk, those caused by using the products and those caused by preventing their use; the morcellation controversy is an example of the latter case given that "there may be greater population benefits and lesser risks from continuing than from discontinuing morcellator use" [56]. However, disproportionate focus on harms caused by use rather than non-use skewed risk perception.

\section{Policy evaluation}

We found no studies examining the role of narratives in policy evaluation.

\section{Knowledge gaps}

Our systematic review highlighted key knowledge gaps concerning the use of narrative interventions in health policy-making. We present, in Table 4, the knowledge gaps relevant to the study design, interventions, setting, population and outcomes in the area of using a narrative to impact health policy-making [42].

\section{Discussion}

\section{Summary and interpretation of findings}

This systematic review identified 18 eligible studies examining the effects of narratives on the different stages of the health policy-making process, except for

Table 4 ldentified knowledge gaps

\begin{tabular}{|c|c|}
\hline Domain & Identified knowledge gaps \\
\hline Study design & $\begin{array}{l}\text { - Lack of experimental or interventional } \\
\text { studies on the impact of narratives on } \\
\text { health policy-making in real-life settings } \\
\text { - Lack of qualitative studies to better } \\
\text { understand the knowledge, beliefs and } \\
\text { attitudes of policy-makers towards narratives }\end{array}$ \\
\hline Intervention & $\begin{array}{l}\text { - Limited evidence on the effects of narratives } \\
\text { (as standalone) independent of other interventions } \\
\text { (e.g. the use of social media) } \\
\text { - Limited description of the narrative intervention } \\
\text { (including frequency and duration of exposure, } \\
\text { content of narrative (e.g. plot and characters) } \\
\text { and perceived credibility of speaker of message) } \\
\text { - Lack of evidence comparing different narrative } \\
\text { formats (e.g. verbal print, audio, video) and } \\
\text { perspectives (first- versus third-person narrative) } \\
\text { - Limited description of the framework or theory } \\
\text { guiding intervention development } \\
\text { - Variations in definitions and operationalisation } \\
\text { of narrative information }\end{array}$ \\
\hline Study setting & $\begin{array}{l}\text { - Limited evidence on the effects of narratives on } \\
\text { health policy-making across cultural settings and } \\
\text { countries } \\
\text { - Limited evidence from low-income countries } \\
\text { - Lack of evidence from the Eastern Mediterranean } \\
\text { Region, Region of the Americas and Western } \\
\text { Pacific Region }\end{array}$ \\
\hline Population & $\begin{array}{l}\text { - Lack of evidence on the effect of moderators, } \\
\text { such as policy-makers' characteristics }\end{array}$ \\
\hline Outcomes & $\begin{array}{l}\text { - Limited evidence on the impact on policy stages } \\
\text { (in general) } \\
\text { - Lack of evidence evaluating the impact on policy } \\
\text { evaluation stage } \\
\text { - No valid measurement of the impact on the } \\
\text { outcomes of interest (e.g. no actual evaluation or } \\
\text { assessment based on perceptions of respondents) }\end{array}$ \\
\hline
\end{tabular}


the policy evaluation stage. The vast majority of included articles describe case studies.

The existing evidence base precludes any robust inferences about the impact of narrative interventions on health policy-making. Nonetheless, the findings suggest that narratives may have a positive influence when used as inspiration and empowerment tools to stimulate policy inquiries; as educational and awareness tools to initiate policy discussions (and gain public support leading to policy prioritisation); and as advocacy and lobbying tools to formulate, adopt or implement policy.

However, there is also evidence of undesirable effects of using narratives $[33,51,56]$. In one case study, narrative use led to widespread insurance reimbursement of a therapy for breast cancer that was later proven to be ineffective [33]. Another case study described how the use of narrative inappropriately exaggerated the perceived risk of a procedure, which led to limiting its use and preventing a large number of patients from its benefits [56]. A third case study described how optimistic 'cure' or 'hope' stories of children with cancer were selectively used to raise money for cancer research that ignored the negative realities such as limited gains made in certain paediatric cancers, the high costs of treatment, and the high prevalence of mental and physical disabilities caused by experimental chemotherapy protocols [51].

The majority of included studies did not provide information on the definition of narratives, the theoretical framework underlying the narrative intervention or the possible predictors of the success of narrative-based interventions. Only one study explicitly discussed how the framing of the attributes of narratives (i.e. sequenced events, characters, time, location, etc.) influenced policy-making differentially in two different parts of Australia (Sydney and Melbourne) [44]. Thus, uncertainties remain about how to construct and present narrative information.

Having said this, we highlight two emerging patterns that might inform the optimal use of narratives. First, all but four studies used a meta-narrative that combined the stories of a large number of people to convey a thematic, systemic story as opposed to focusing on a single event or individual (i.e. episodic stories). Second, the importance of establishing a relationship with media outlets and maximising opportunities to disseminate the narrative information was emphasised in several studies. Indeed, six of the included studies highlighted the involvement of media as an important catalyst for policy change $[43,45,49,50,54,56]$. In four studies, the narrative was picked up by media $[43,45,49,56]$ whereas, in two studies, active effort was made to engage the media and maximise the reach of the narrative information [50,54]. Unfortunately, there is also a lack of reliable evidence on the use of media interventions to influence health policy-making [60].

\section{Strengths and limitations}

To our knowledge, this is the first systematic review examining the effects of narrative-based interventions on the health policy-making process. Strengths of our methodology include the pre-publication of a protocol, a rigorous and transparent review process, and adherence to standard methods for reporting systematic reviews [61, 62]. In addition, we searched multiple databases and included both published and the grey literature.

A major challenge in conducting this review was how to best conceptualise and categorise narratives given the absence of clear definition and operationalisation of narrative information. This made it difficult to decide on the eligibility of some of the studies and to abstract data. This is why we relied on a consensus approach to screening and data abstraction, and iteratively revised our conceptualisation of narrative. Although we did search resources that include grey literature (e.g. Google Scholar and the WHO Global Health Library and Communication and Mass Media Complete), we could have searched additional resources such as websites of NGOs, advocacy groups and donors. Further, while some might criticise our use of stages heuristic framework, considered by some scholars to assume linearity of the policy-making process, we opted to use this framework as it is considered one of the most prominent public policy frameworks. More importantly, it did facilitate synthesis of findings and provide a simplified and useful way to view the entire policy process $[37,38]$.

\section{Knowledge gaps}

A major gap relates to the poor methodological rigor of the included studies. All included studies lacked actual evaluation of effectiveness or explicit evidence for the link between the intervention and the outcome. Additionally, in the majority of the included studies, the narrative component was part of a multicomponent intervention, and thus the evidence associated with the narrative may be indirect or confounded by other components of the intervention [34]. The aforementioned limitations made it difficult to make any inferences on effectiveness of narrative interventions in the health policy-making process.

Moreover, the very limited description of the narrative interventions was challenging, particularly given that they qualify as complex interventions $[63,64]$. Important aspects of these interventions include frequency and duration of exposure to a narrative, content of a narrative (for example, plot, characters, and moral of story) and perceived credibility of the speaker or message. These aspects are important to understand the specific narrative intervention that was tested, what component of the intervention was effective, and the superiority of one format over another.

Additionally, the majority of included studies failed to provide information about what framework or theory 
guided intervention development and outcome measurement. Several theories of narrative persuasion have been identified in the literature [15, 17, 18]. Thus, without such information, it would be difficult to understand the mechanism by which narrative interventions persuade health policy-makers and lead to change. Moreover, we could not determine the effect of moderators, such as the policy-makers' characteristics on the effectiveness of the narratives.

While beyond the scope of this systematic review, we have identified studies assessing message-framing involving hypothetical scenarios on the attitudes, beliefs and intentions of health policy-makers and legislators [65-68]. These warrant further exploration to complement the evidence base on the use of narratives in health policy-making in real settings.

\section{Comparison to other systematic reviews}

While we did not identify any other systematic review of narratives in the field of health policy-making, we identified many in the field of clinical decision-making [2, 21, 69]. Perrier and Ginis found "consistent evidence supporting the efficacy of narratives at changing screening behavior" [69], but mixed evidence supporting an advantage of narratives over providing statistical information for screening behaviour and its determinants. Winterbottom et al. [2] found limited evidence suggesting that narratives affected an individual's medical decisions, but it was unclear why narratives affected the decision-making process or whether they facilitated or biased decision-making. Bekker et al. [21] concluded that there is insufficient evidence that adding personal stories to patient decision aids enhances their effectiveness to support people to make informed decisions.

\section{Implications for research}

Despite the increased interest in narratives [6, 23, 24, 70], the evidence base on their impact on health policy-making is of very low certainty. This systematic review highlights the challenges of assessing the impact of narrative interventions on health policy-making given the complex nature of these interventions, the difficulties in using experimental methods, and the multiple factors influencing the policy-making process $[34,64,71]$. Therefore, more rigorous primary research is needed to gain a better understanding of narrative interventions beyond whether or not they are effective to why and under what circumstances.

Given that narratives qualify as complex interventions, a particular focus should be on conducting realist evaluation studies. Unlike traditional impact evaluation that establishes whether change in outcomes can be directly attributed to an intervention, realist evaluation focuses on the processes and contexts of implementation that yield impact [72]. Thus, by examining 'what works, for whom and why', insights are gained about the interactions between interventions, implementers and health systems that make interventions more or less successful [73, 74]. This is critical to inform the design of context-specific strategies and understand how the influence of narrative information can differ across various health systems and socioeconomic realities. Additionally, qualitative studies can help explore the knowledge, beliefs and attitudes of policy-makers towards narrative information, including their role in the policy-making process.

In addition, researchers are encouraged to promote better reporting of studies in this field, taking into account guidelines for reporting of complex interventions when describing the narrative interventions $[75,76]$. Importantly, experts in the field should establish clear definition and operationalisation of narratives to allow better research and communication on the topic.

Funding agencies have an important role in advancing knowledge and un-tapping the potential for using narrative to influence health policy-making by supporting studies that address the aforementioned knowledge gaps. This would also align with global calls for more effective and innovative approaches to bridge the gap between research and policy-making [77-80].

\section{Implications for policy}

Our findings suggest that, while narratives may have a positive influence on health policy change, they may sometimes lead to undesirable outcomes. Findings also allude to potential pitfalls and ethical concerns that should be taken into consideration when using narratives. First, because of the selective nature of narratives, narrators may omit details of a story or exaggerate it, so the story may not be representative of the larger reality (for example, the case of childhood cancer where optimistic 'cure' or 'hope' stories were selectively used that ignored the negative realities). Second, the reliance on narratives without scientific evidence may lead policy-makers to adopt policies that may be ineffective or even harmful or waste resources (for example, the case of reimbursing a therapy for breast cancer that was later proven to be ineffective). Third, narratives may produce biased results based on the views of one or a select number of individuals (for example, the case of discontinuing morcellator use). Because of the affective nature of narratives, policy-makers may give higher priority to diseases with more tragic stories such as cancer and HIV at the expense of other diseases with a similar or higher burden such as cardiovascular diseases [33, 58].

These limitations and potential pitfalls do not mean that there should be no place for narratives in informing health policy-making. However, it does mean that narratives need to be held to standards of validity [6, 81, 82]. For instance, Hyman [83] insists that those using narratives provide persuasive evidence of typicality and completeness 
before assigning any weight to their stories. Sharf [33] calls for effectively combining the emotional pathos of stories with rhetorical proof.

In light of the above, we suggest using narratives that are rooted in evidence to influence health policy-making. Those designing or using narrative information need to consider all the above discussed challenges and potential pitfalls. This would be best achieved by building strong and effective partnerships between 'evidence experts' and those involved in advocacy. Additionally, narratives could be used to support policies that are based on widely agreed on principles, such as those of human rights and medical ethics like access to basic health services and non-discriminatory health policies.

\section{Conclusion}

Despite the increased interest in narratives, the existing evidence base precludes any robust inferences about the impact of narrative interventions on health policy-making. Rigorous research supporting impact on health policymaking is still needed.

\section{Additional files}

Additional file 1: Search strategy. (DOCX $21 \mathrm{~kb})$

Additional file 2: Excluded studies and reasons for exclusion. (PDF $767 \mathrm{~kb}$ )

Additional file 3: Assessment of the reporting of included case studies. (PDF $338 \mathrm{~kb}$ )

\section{Acknowledgements}

We would like to thank Ms Aida Farha for her help in validating the search strategy.

\section{Funding}

This systematic review was funded by the Alliance for Health Policy and Systems Research, WHO, Geneva. The funding body had no role in the design of the study, collection, analysis and interpretation of data, and in writing the manuscript.

\section{Availability of data and materials}

All relevant data are within the paper and its additional files.

\section{Authors' contributions \\ EAA, FJ and RF conceived the study. EA, FJ, RF and EL contributed to the study design. RF and EAA designed and ran the search strategy. RF, MN, NH and KA screened the articles for eligibility. RF, MN, NH and KA abstracted data from eligible studies. RF and MN assessed methodological quality of included studies. RF, EA and FE contributed to the analysis and interpretation of results. RF, EA, FE and EL contributed to writing up of the manuscript. All authors read and approved the final manuscript.}

\section{Ethics approval and consent to participate}

Not applicable.

\section{Consent for publication}

Not applicable.

\section{Competing interests}

The authors declare that they have no competing interests.

\section{Publisher's Note}

Springer Nature remains neutral with regard to jurisdictional claims in published maps and institutional affiliations.

\section{Author details}

${ }^{1}$ Center for Systematic Review for Health Policy and Systems Research, American University of Beirut, Beirut, Lebanon. ${ }^{2}$ Department of Health Management and Policy, Faculty of Health Sciences, American University of Beirut, Beirut, Lebanon. ${ }^{3}$ Alliance for Health Policy and Systems Research, World Health Organization, Geneva, Switzerland. ${ }^{4}$ Department of Internal Medicine, American University of Beirut, Beirut, Lebanon.

Received: 8 August 2018 Accepted: 6 February 2019

Published online: 05 March 2019

\section{References}

1. Slater MD, Buller DB, Waters E, Archibeque M, LeBlanc M. A test of conversational and testimonial messages versus didactic presentations of nutrition information. J Nutr Educ Behav. 2003;35(5):255-9.

2. Winterbottom A, Bekker HL, Conner M, Mooney A. Does narrative information bias individual's decision making? A systematic review. Soc Sci Med. 2008;67(12):2079-88.

3. Toolan M. Narrative: A Critical Linguistic Introduction. London: Routledge; 2012.

4. Goodwyn E. Recurrent motifs as resonant attractor states in the narrative field: a testable model of archetype. J Anal Psychol. 2013;58(3): 387-408.

5. Chatman SB. Story and discourse: Narrative structure in fiction and film. Ithaca: Cornell University Press; 1980.

6. Dahlstrom MF. Using narratives and storytelling to communicate science with nonexpert audiences. Proc Natl Acad Sci U S A. 2014;111(Suppl 4): 13614-20.

7. Jones MD, McBeth MK. A narrative policy framework: clear enough to be wrong? Policy Stud J. 2010;38(2):329-53.

8. Kreuter MW, Green MC, Cappella JN, Slater MD, Wise ME, Storey D, et al. Narrative communication in cancer prevention and control: a framework to guide research and application. Ann Behav Med. 2007; 33(3):221-35

9. Avraamidou $\mathrm{L}$, Osborne J. The role of narrative in communicating science. Int J Sci Educ. 2009:31(12):1683-707.

10. Steiner JF. The use of stories in clinical research and health policy. JAMA. 2005;294(22):2901-4

11. Peters EVD, Slovic P, Mertz C, Mazzocco K, Dickert S. Numeracy and decision making. Psychol Sci. 2006;17(5):407-13.

12. Kreuter MW, Holmes K, Alcaraz K, Kalesan B, Rath S, Richert M, et al. Comparing narrative and informational videos to increase mammography in low-income African American women. Patient Educ Couns. 2010;81(Suppl):S6-14.

13. Reinard JC. The empirical study of the persuasive effects of evidence the status after fifty years of research. Hum Commun Res. 1988;15(1):3-59.

14. Shen F, Sheer VC, Li R. Impact of narratives on persuasion in health communication: A meta-analysis. J Advert. 2015;44(22):105-13.

15. Cacioppo JT, Petty RE. The Elaboration Likelihood Model of Persuasion. Provo, UT: ACR North American Advances; 1984.

16. Green MC, Brock TC. The role of transportation in the persuasiveness of public narratives. J Pers Soc Psychol. 2000;79(5):701-21.

17. Green MC, Brock TC. In the mind's eye: transportation-imagery model of narrative persuasion. In: Green MC, Strange JJ, Brock TC (Eds.). Narrative Impact: Social and Cognitive Foundations. Mahwah, NJ: Lawrence Erlbaum Associates Publishers; 2002. p. 315-41).

18. Moyer-Gusé E. Toward a theory of entertainment persuasion: explaining the persuasive effects of entertainment-education messages. Communication Theory. 2008;18(3):407-25.

19. Price RA. Suspenseful Narratives and Transportation; Explorations of Individual Difference Factors and Transportation as Predictors of StoryConsistent Attitudes. ETD Archive. 2017;994. https://engagedscholarship. csuohio.edu/etdarchive/994. Accessed 25 Feb 2019.

20. Slater MD. Entertainment education and the persuasive impact of narratives. In: Green MC, Strange JJ, Brock TC (Eds.). Narrative Impact: Social and Cognitive Foundations. Mahwah, NJ: Lawrence Erlbaum Associates Publishers; 2002. p. 157-81. 
21. Bekker HL, Winterbottom AE, Butow P, Dillard AJ, Feldman-Stewart D, Fowler FJ, et al. Do personal stories make patient decision aids more effective? A critical review of theory and evidence. BMC Med Inform Decis Mak. 2013;13(Suppl 2):S9.

22. de Wit JB, Das E, Vet R. What works best: objective statistics or a personal testimonial? An assessment of the persuasive effects of different types of message evidence on risk perception. Health Psychol. 2008;27(1):110-5.

23. Davidson B. The role of narrative change in influencing policy. 2016. https:// onthinktanks.org/articles/the-role-of-narrative-change-in-influencing-policy/. Accessed 25 Feb 2019.

24. Epstein D, Heidt J, Farina C. The value of words: Narrative as evidence in policymaking. Evidence Policy. 2014;10(2):243-58.

25. Cairney P, Oliver K. Evidence-based policymaking is not like evidence-based medicine, so how far should you go to bridge the divide between evidence and policy? Health Res Policy Syst. 2017;15(1):35.

26. Choi BC, Pang T, Lin V, Puska P, Sherman G, Goddard M, et al. Can scientists and policy makers work together? J Epidemiol Community Health. 2005; 59(8):632-7.

27. Brownson RC, Chriqui JF, Stamatakis KA. Understanding evidence-based public health policy. Am J Public Health. 2009;99(9):1576-83.

28. Greenlick MR, Goldberg B, Lopes P, Tallon J. Health policy roundtable--view from the state legislature: translating research into policy. Health Serv Res. 2005;40(2):337-46.

29. Bogenschneider K CT. Evidence-based policymaking: insights from policyminded researchers and research-minded policy makers. J Marriage Family. 2011;73(3):687-9.

30. Cairney P, Kwiatkowski R. How to communicate effectively with policymakers: combine insights from psychology and policy studies. Palgrave Commun. 2017;3(1):37.

31. McDonough JE. Using and misusing anecdote in policy making. Health Aff (Millwood). 2001;20(1):207-12.

32. Jewell CJ, Bero LA. "Developing good taste in evidence": facilitators of and hindrances to evidence-informed health policymaking in state government. Milbank Q. 2008;86(2):177-208.

33. Sharf BF. Out of the closet and into the legislature: breast cancer stories. Health Aff (Millwood). 2001;20(1):213-8.

34. Buse K, Nicholas M, Walt G. Making Health Policy. 2nd ed. Maidenhead: Open University Press; 2012.

35. Verboom B, Montgomery P, Bennett S. What factors affect evidenceinformed policymaking in public health? Protocol for a systematic review of qualitative evidence using thematic synthesis. Syst Rev. 2016;5:61.

36. Mays N, Pope C, Popay J. Systematically reviewing qualitative and quantitative evidence to inform management and policy-making in the health field. J Health Serv Res Policy. 2005;10(Suppl 1):6-20.

37. Sabatier P. Theories of the Policy Process. 1st ed. Colorado: Westview Press; 1999.

38. Walt G, Shiffman J, Schneider H, Murray SF, Brugha R, Gilson L. 'Doing' health policy analysis: methodological and conceptual reflections and challenges. Health Policy Plan. 2008;23(5):308-17.

39. Benoit F. Public Policy Models and their Usefulness in Public Health: The Stages Model. Québec: National Collaborating Centre for Healthy Public Policy, Institut national de santé publique; 2013.

40. Kulaç $\mathrm{O}$, Özgür $\mathrm{H}$. An overview of the stages (heuristics) model as a public policy analysis framework. Eur Sci J. 2017;13(12):144-57.

41. Rodgers M, Thomas S, Harden M, Parker G, Street A, Eastwood A. Developing a Methodological Framework for Organisational Case Studies: A Rapid Review and Consensus Development Process. Southampton: Health Services and Delivery Research; 2016.

42. Miake-Lye IM, Hempel S, Shanman R, Shekelle PG. What is an evidence map? A systematic review of published evidence maps and their definitions, methods, and products. Syst Rev. 2016;5:28.

43. Johnson K, Minogue G, Hopklins R. Inclusive research: making a difference to policy and legislation. J Appl Res Intellect Disabil. 2014;27(1):76-84.

44. Fitzgerald JL. Supervised injecting facilities: a case study of contrasting narratives in a contested health policy arena. Crit Public Health. 2013;23(1):77-94.

45. Umuhoza C, Oosters B, van Reeuwijk M, Vanwesenbeeck I. Advocating for safe abortion in Rwanda: how young people and the personal stories of young women in prison brought about change. Reprod Health Matters. 2013;21(41):49-56.

46. Leith KH, Phillips L. "In Their Own Voices" Using Qualitative Research and Consumer Narratives for Systems Change. Soc Policy J. 2006;4(3-4):19-35.
47. Wilcock PM, Brown GC, Bateson J, Carver J, Machin S. Using patient stories to inspire quality improvement within the NHS Modernisation Agency collaborative programmes. J Clin Nurs. 2003;12(3):422-30.

48. Neuhausen K. Awakening advocacy: how students helped save a safety-net hospital in Georgia. Health Aff (Millwood). 2013;32(6):1161-4.

49. Shi L. Micro-blogs, online forums, and the birth-control policy: social media and the politics of reproduction in China. Cult Med Psychiatry. 2014;38(1):115-32.

50. Slaton AE, Cecil CW, Lambert LE, King T, Pearson MM. What a difference family-driven makes: stories of success and lessons learned. Am J Community Psychol. 2012:49(3-4):538-45.

51. Krueger G. "For Jimmy and the boys and girls of America": publicizing childhood cancers in twentieth-century America. Bull Hist Med. 2007; 81(1):70-93.

52. MacGregor H, Mills E. Framing rights and responsibilities: accounts of women with a history of AIDS activism. BMC Int Health Hum Rights. 2011; 11(Suppl 3):S7.

53. Marcus PM, Huang GC, Beck V, Miller MJ. The impact of a primetime cancer storyline: from individual knowledge and behavioral intentions to policylevel changes. J Cancer Educ. 2010;25(4):484-9.

54. MacKenzie R, Imison M, Chapman S, Holding S. Mixed messages and a missed opportunity: Australian news media coverage of Clare Oliver's campaign against solaria. Med J Aust. 2008;189(7):371-4.

55. Trossman S. MNA president uses personal story to push for needlestick legislation. Am Nurse. 1999;31(3):13.

56. Rosenbaum L. N-of-1 policymaking--tragedy, trade-offs, and the demise of morcellation. N Engl J Med. 2016;374(10):986-90.

57. Lorenzo T. "We are also travellers": An action story about disabled women mobilising for an accessible public transport system in Khayelitsha and Nyanga, Cape Metropole, South Africa. South Afr J Occup Ther. 2008;38(1):32-40.

58. Beck CS, Aubuchon SM, McKenna TP, Ruhl S, Simmons N. Blurring personal health and public priorities: an analysis of celebrity health narratives in the public sphere. Health Commun. 2014;29(3):244-56.

59. Lander $M$. The fight for a life-saving drug: a personal perspective. Med J Aust. 2007;187(11-12):706-8.

60. Bou-Karroum L, El-Jardali F, Hemadi N, Faraj Y, Ojha U, Shahrour M, et al. Using media to impact health policy-making: an integrative systematic review. Implement Sci. 2017;12(1):52.

61. Moher D, Liberati A, Tetzlaff J, Altman DG. Preferred reporting items for systematic reviews and meta-analyses: the PRISMA statement. Int I Surg. 2010;8(5):336-41.

62. Higgins JP, Green S. Cochrane Handbook for Systematic Reviews of Interventions. Chichester: Wiley; 2011.

63. Scott SD, Hartling L, O'Leary KA, Archibald M, Klassen TP. Stories-a novel approach to transfer complex health information to parents: a qualitative study. Arts Health. 2012;4(2):162-73.

64. Greenhalgh T, Collard A, Begum N. Sharing stories: complex intervention for diabetes education in minority ethnic groups who do not speak English. BMJ. 2005;330(7492):628.

65. Brownson RC, Dodson EA, Stamatakis KA, Casey CM, Elliott MB, Luke DA, et al. Communicating evidence-based information on cancer prevention to state-level policy makers. J Natl Cancer Inst. 2011;103(4):306-16.

66. Brownson RC, Dodson EA, Kerner JF, Moreland-Russell S. Framing research for state policymakers who place a priority on cancer. Cancer Causes Control. 2016;27(8):1035-41.

67. Morshed AB, Dodson EA, Tabak RG, Brownson RC. Comparison of research framing preferences and information use of state legislators and advocates involved in cancer control, United States, 2012-2013. Prev Chronic Dis. 2017;14:E10.

68. Niederdeppe J, Roh S, Dreisbach C. How narrative focus and a statistical map shape health policy support among state legislators. Health Commun. 2016:31(2):242-55

69. Perrier M-J, Martin Ginis KA. Narrative interventions for health screening behaviours: A systematic review. J Health Psychol. 2017;22(3):375-93.

70. Greenhalgh T. Cultural Contexts of Health: The Use of Narrative Research in the Health Sector. Copenhagen: WHO Health Evidence Network Synthesis Reports; 2016.

71. LeBron AM, Schulz AJ, Bernal C, Gamboa C, Wright C, Sand S, et al. Storytelling in community intervention research: lessons learned from the walk your heart to health intervention. Prog Community Health Partnersh. 2014;8(4):477-85. 
72. Adams A, Sedalia S, McNab S, Sarker M. Lessons learned in using realist evaluation to assess maternal and newborn health programming in rural Bangladesh. Health Policy Plan. 2016;31(2):267-75.

73. Marchal B, Van Belle S, Van Olmen J, Hoerée T, Kegels G, Marchal B, Van Belle S, Van Olmen J, Hoerée T, Kegels G. Is realist evaluation keeping its promise? A review of published empirical studies in the field of health systems research. Evaluation. 2012;18(2):192-212.

74. Fletcher A, Jamal F, Moore G, Evans RE, Murphy S, Bonell C. Realist complex intervention science: applying realist principles across all phases of the Medical Research Council framework for developing and evaluating complex interventions. Eval. 2016;22(3):286-303.

75. Mohler R, Kopke S, Meyer G. Criteria for Reporting the Development and Evaluation of Complex Interventions in healthcare: revised guideline (CReDECI 2). Trials. 2015;16:204.

76. Craig P, Dieppe P, Macintyre S, Michie S, Nazareth I, Petticrew M. Developing and evaluating complex interventions: the new Medical Research Council quidance. Int J Nurs Stud. 2013;50(5):587-92.

77. Uzochukwu B, Onwujekwe O, Mbachu C, Okwuosa C, Etiaba E, Nystrom ME, et al. The challenge of bridging the gap between researchers and policy makers: experiences of a Health Policy Research Group in engaging policy makers to support evidence informed policy making in Nigeria. Glob Health. 2016;12(1):67.

78. Langlois EV, Becerril Montekio V, Young T, Song K, Alcalde-Rabanal J, Tran N. Enhancing evidence informed policymaking in complex health systems: lessons from multi-site collaborative approaches. Health Res Policy Syst. 2016;14:20.

79. Shroff Z, Aulakh B, Gilson L, Agyepong IA, El-Jardali F, Ghaffar A. Incorporating research evidence into decision-making processes: researcher and decision-maker perceptions from five low- and middle-income countries. Health Res Policy Syst. 2015;13:70.

80. van de Goor I, Hamalainen RM, Syed A, Juel Lau C, Sandu P, Spitters H, et al. Determinants of evidence use in public health policy making: results from a study across six EU countries. Health Policy. 2017;121(3):273-81.

81. Moezzi M, Janda KB, Rotmann S. Using stories, narratives, and storytelling in energy and climate change research. Energy Res Soc Sci. 2017;31:1-10.

82. Stamatakis KA, McBride TD, Brownson RC. Communicating prevention messages to policy makers: the role of stories in promoting physical activity. J Phys Act Health. 2010;7(Suppl 1):S99-107.

83. Hyman DA. Do good stories make for good policy? J Health Polit Policy Law. 2000;25(6):1149-55.

Ready to submit your research? Choose BMC and benefit from:

- fast, convenient online submission

- thorough peer review by experienced researchers in your field

- rapid publication on acceptance

- support for research data, including large and complex data types

- gold Open Access which fosters wider collaboration and increased citations

- maximum visibility for your research: over $100 \mathrm{M}$ website views per year

At BMC, research is always in progress.

Learn more biomedcentral.com/submissions 